\title{
Erratum to: Melting the hydrous, subarc mantle: the origin of primitive andesites
}

\author{
Alexandra L. Mitchell ${ }^{1}$ Timothy L. Grove ${ }^{1}$
}

Published online: 23 November 2015

(C) Springer-Verlag Berlin Heidelberg 2015

\section{Erratum to: Contrib Mineral Petrol (2015) 170:13 DOI 10.1007/s00410-015-1161-4}

What we had intended to appear as the last section of our paper describing the supplementary material was instead published as the first electronic supplementary material (ESM). Because this section (Supplemental Material) was inserted into the ESM, the numerical references in the text of the section do not coincide with the supplementary materials that are included with the paper. Below, the number of each supplement has been increased by one to correct the error.

In addition, the erroneously published Supplemental Material section of the paper was the only place that referred to an excel model presented with the manuscript. The excel model was designed to be used by the community to estimate the conditions under which primitive lavas last equilibrated with the mantle. The spreadsheet allows the user to estimate either (1) pressure (GPa) and temperature $\left({ }^{\circ} \mathrm{C}\right)$ or $(2) \mathrm{H}_{2} \mathrm{O}(\mathrm{wt} \%)$ and temperature $\left({ }^{\circ} \mathrm{C}\right)$. We include that excel model as supplementary material with this erratum so that readers of the paper will be aware of this resource.

The online version of the original article can be found under doi:10.1007/s00410-015-1161-4.

Electronic supplementary material The online version of this article (doi:10.1007/s00410-015-1204-x) contains supplementary material, which is available to authorized users.

Alexandra L. Mitchell

ala@mit.edu

1 Department of Earth, Atmospheric and Planetary Sciences, Massachusetts Institute of Technology, Cambridge,

MA 02139, USA
Description of Supplementary Material

SM1. Table of contents and description of Electronic Supplementary Material

SM2. Experimental methods

SM3. Analytical methods

SM4. Modelling methods

SM5. Model in Excel

An excel spreadsheet is included in online supplemental materials to aid with use of the model presented. The spreadsheet calculates the first three equations in Table 6 using two methods: it calculates (1) $P(\mathrm{GPa})$ and $T\left({ }^{\circ} \mathrm{C}\right)$ of last equilibration for known $\mathrm{H}_{2} \mathrm{O}$ contents of last equilibration or (2) $\mathrm{H}_{2} \mathrm{O}(\mathrm{wt} \%)$ and $T\left({ }^{\circ} \mathrm{C}\right)$ of last equilibration when the pressure $(\mathrm{GPa})$ of last equilibration is known. To use the spreadsheet, enter your compositions into the 'Input' sheet as well as your known $\mathrm{H}_{2} \mathrm{O}$ or pressure for each composition. The sheet goes through the following steps:

1. renormalizes the compositions;

2. converts compositions to molar values;

3. converts all oxides to single cation units;

4. converts to single oxygen units;

5. calculates the $\mathrm{Cpx}, \mathrm{Ol}, \mathrm{Plag}, \mathrm{Qz}$ endmembers of Tormey et al. (1987) [corrected in Grove (1993)];

6. calculates $P$ and $T$ or $\mathrm{H}_{2} \mathrm{O}$ and $T$ using the equations in Table 6.

The results of each step are recorded in the 'Calculations' sheet. Final values are reported in the 'Output' sheet. Sample names are automatically copied across each sheet for easy analysis of results. 